\title{
Depressive Symptoms, Cardiac Anxiety, and Fear of Body Sensations in Patients with Non- Cardiac Chest Pain, and Their Relation to Healthcare-Seeking Behavior: A Cross- Sectional Study
}

Ghassan Mourad, Anna Strömberg, Peter Johansson and Tiny Jaarsma

\section{Linköping University Post Print}

\section{Tweet}

N.B.: When citing this work, cite the original article.

The original publication is available at www.springerlink.com:

Ghassan Mourad, Anna Strömberg, Peter Johansson and Tiny Jaarsma, Depressive Symptoms, Cardiac Anxiety, and Fear of Body Sensations in Patients with Non-Cardiac Chest Pain, and Their Relation to Healthcare-Seeking Behavior: A Cross-Sectional Study, 2015, The patient. http://dx.doi.org/10.1007/s40271-015-0125-0

Copyright: Springer Verlag (Germany) / Adis http://www.springerlink.com/?MUD=MP

Postprint available at: Linköping University Electronic Press http://urn.kb.se/resolve?urn=urn:nbn:se:liu:diva-117694 
Depressive symptoms, cardiac anxiety and fear of body sensations in patients with noncardiac chest pain, and their relation to healthcare seeking behaviour: A cross-sectional study

\section{Running header:}

Psychological symptoms and healthcare use in non-cardiac chest pain

Ghassan Mourad MSc, RN,*, Anna Strömberg, PhD, RN, FAAN ${ }^{\mathrm{b}}$, Peter Johansson, PhD, $\mathrm{RN}^{\mathrm{b}}$ \& Tiny Jaarsma, PhD, RN, FAAN ${ }^{\mathrm{a}}$

(a) Department of Social and Welfare Studies, Linköping University, Norrköping, Sweden

(b) Department of Cardiology and Department of Medical and Health Sciences, Linköping University, Linköping, Sweden

*Corresponding author: Ghassan Mourad

Address: Linköpings universitet, Kungsgatan 40 S-601 74 Norrköping

Telephone: +4611363514

Fax: +4611 125448

E-mail: ghassan.mourad@liu.se

Word count: 3628 (abstract and references excluded) 


\section{ABSTRACT}

Background: Patients with non-cardiac chest pain (NCCP) suffer from recurrent chest pain and use a substantial amount of healthcare resources.

Objective: to explore the prevalence of depressive symptoms, cardiac anxiety and fear of body sensations in patients discharged with a NCCP diagnosis. Additionally, to describe how depressive symptoms, cardiac anxiety and fear of body sensations are related to each other and to healthcare seeking behaviour.

Methods: Cross-sectional design. Data were collected between late October 2013 and early January 2014 in 552 patients with NCCP from four hospitals in southeast Sweden, using the Patient Health Questionnaire-9, Cardiac Anxiety Questionnaire and Body Sensations Questionnaire.

Results: About $26 \%(n=141)$ of the study participants reported at least moderate depressive symptoms, $42 \%(n=229)$ reported at least moderate cardiac anxiety, and $62 \%(n=337)$ reported some degree of fear of body sensations. We found a strong positive relationship between depressive symptoms and cardiac anxiety $\left(\mathrm{r}_{\mathrm{s}}=0.49, \mathrm{p}<.01\right)$, depressive symptoms and fear of body sensations $\left(\mathrm{r}_{\mathrm{s}}=0.50, \mathrm{p}<.01\right)$, and cardiac anxiety and fear of body sensations $\left(r_{s}=0.56, p<.01\right)$. About $60 \%$ of the participants sought care due to chest pain once, $26 \% 2-3$ times, and the rest more than 3 times. In a multivariable regression analysis, and after adjusting for multi-morbidity, cardiac anxiety was the only variable independently associated with healthcare seeking behaviour.

Conclusions: Patients with NCCP and many healthcare consultations had high levels of depressive symptoms and cardiac anxiety, and moderate levels of fear of body sensations. Cardiac anxiety had the strongest relationship with healthcare seeking behaviour, and may 
therefore be an important target for intervention to alleviate suffering and reduce healthcare use and costs.

\section{Key points for decision makers}

- Patients with non-cardiac chest pain and many healthcare consultations experience high levels of depressive symptoms and cardiac anxiety, and moderate levels of fear of body sensations.

- Depressive symptoms, cardiac anxiety and fear of body sensations are strongly related to each other and to healthcare seeking behaviour.

- Cardiac anxiety influence healthcare seeking behaviour the most and should therefore be targeted with interventions to improve patient outcomes and reduce healthcare costs. 


\section{INTRODUCTION}

Non-cardiac chest pain (NCCP) is very common [1], with more than half of the patients consulting the emergency department due to chest pain being diagnosed with NCCP [2-4]. There may be many causes for NCCP, e.g. musculoskeletal, gastrointestinal, pulmonary and psychological, and more than one potential cause can be prevalent [1,5,6]. Ideally, appropriate management of these patients should be investigation and treatment of the underlying cause when acute cardiac disease has been ruled out. However, despite continuous chest pain, many patients are discharged without a clear explanation of the cause for their chest pain $[7,8]$. Many of these patients are convinced that they have an undetected cardiac disease, and they therefore avoid activities that they think might be harmful to their heart $[9,10]$, even though they have been reassured that they do not have a medical problem [11].

Despite the favourable prognosis $[4,5,12,13]$, patients with NCCP suffer from recurrent chest pain and have been found to use out-patient healthcare to the same extent as patients with cardiac pain [14,15], leading to high healthcare and societal costs [16-19]. A possible mechanism for this can be psychological distress, although there could be physical causes that have not been detected yet. Several studies demonstrate an association between depressive symptoms, anxiety, fear of body sensations and NCCP, and highlight the negative impact these factors have on patients' health-related quality of life, daily life, pain experience, and healthcare seeking behaviour [6,20-24]. Yet, the relationship between these psychological factors in patients with NCCP is not fully elucidated. Insight into the interrelationship between them and the relationship to healthcare seeking behaviour enables us to design interventions to improve patient outcomes and avoid unnecessary suffering, and to reduce healthcare use in the long run. We therefore aimed to explore the prevalence of depressive symptoms, cardiac anxiety and fear of body sensations in patients admitted to hospital due to chest pain and discharged with a non-cardiac chest pain diagnosis. Further, we aimed to 
describe how depressive symptoms, cardiac anxiety and fear of body sensations are related to each other and to healthcare seeking behaviour.

\section{METHODS}

This study has a cross-sectional design. The study was approved by the Regional Ethical Review Board in Linköping, Sweden (code 2013/223-31), and was conducted according to the Declaration of Helsinki. Data collection was also approved by all clinic managers.

\subsection{Study participants}

Patients eligible for the study were those older than 18 years who had sought medical care due to chest pain and been diagnosed with NCCP (ICD 10-code R07.2, precordial chest pain; ICD 10-code R07.3, other chest pain; ICD 10-code R07.4, chest pain unspecified; and ICD 10code Z03.4, observation for suspected myocardial infarction). Eligible study participants were identified within one month from the day of discharge from the emergency, medical, and cardiac departments at three county hospitals and one university hospital within a region in southeast Sweden.

\subsection{Data collection and procedure}

Data were collected consecutively between late October 2013 and early January 2014. Potential study participants were identified using lists of patients discharged with any of the above mentioned NCCP diagnoses. These lists were given to the research team by a secretary at the departments once every month during the data collection period. Study information, written informed consent form, questionnaires, and a pre-stamped envelope were sent to all eligible patients. The invited patients were offered to contact the research team in case of questions or remarks. Patients consented to study participation by signing and returning the written informed consent form together with the completed questionnaires. A lottery ticket worth 1 Euro was sent to those participating in the study to thank them for completing the 
questionnaires. One reminder was sent to those who did not answer within 3 weeks. Patients not willing to participate and those under investigation to rule out cardiac disease were not contacted further.

\subsection{Measurement instruments}

All data was self-reported since we did not have access to patients' medical records. Data on socio-demographical variables were collected with a questionnaire. Regarding diseases/health complaints, we chose to list a number of the most common (Table 2) and the participants were asked to respond to whether they had any of them. The alternatives were: "No; Yes, but I have not consulted a physician/had treatment last year; or Yes, I have consulted a physician/had treatment last year”. Healthcare seeking behaviour was determined by asking the participants the following self-developed question: "In the last year, how many times did you seek care due to chest pain?” Answers were predetermined to the categories: “1, 2-3, or >3”. Patients' self-reports on e.g. selected chronic diseases have been found to be fairly accurate compared to physician reports [25].

\subsubsection{Depressive symptoms}

The Patient Health Questionnaire-9 (PHQ-9) was used to measure depressive symptoms. The PHQ-9 is a 9-item questionnaire with the potential to both establish depressive disorder diagnoses and to grade the depressive symptom severity. Items are rated on a 4-point scale from 0 to 3, ranging from "not at all” to "nearly every day”. At a score of 10 or higher, the PHQ-9 has a sensitivity for major depression of $88 \%$, a specificity of $88 \%$, and a positive likelihood ratio of 7.1. The PHQ-9 has shown to have high internal consistency with a Cronbach's $\alpha$ of 0.89 in a primary care study [26]. 


\subsubsection{Cardiac Anxiety}

The Cardiac Anxiety Questionnaire (CAQ), comprising 18 items, was used to assess cardiac anxiety, which is fear of cardiac-related stimuli and sensations. Each item is rated on a 5-point scale from 0 (never) to 4 (always). The CAQ consists of a total score and three subscales for fear, avoidance, and heart-focused attention. The total score is computed as the mean value of all items. Subscale scores are similarly computed as the mean of the relative frequency ratings for each of the items in each subscale. By using the mean values, scores from the total CAQ and the subscales can be easily compared. Higher scores indicate greater cardiac anxiety [27]. For example, anxious patients without panic had scores of $18.8 \pm 8.9$ and patients with panic had scores of $28.7 \pm 12.7$ [28]. The total scale and the three subscales have shown to have adequate reliability and convergent and divergent validity. Cronbach's $\alpha$ for the total scale was 0.83 , and for the subscales these were 0.83 for fear, 0.82 for avoidance and 0.69 for heartfocused attention [27].

\subsubsection{Fear of Body Sensations}

The Body Sensations Questionnaire (BSQ) is a 17-item scale used to measure fear of body sensations, such as palpitations, dizziness and sweating. Items are rated on a 5-point scale from 1 to 5, ranging from "not frightened or worried by this sensation” to “extremely frightened by this sensation”. The total score is computed as the mean value of all items. Higher scores indicate more fear of body sensations [29]. For example, normal controls had scores of $1.80 \pm 0.59$, patients with panic between $2.79 \pm 0.4$ and $3.09 \pm 0.6$, and patients with agoraphobia $3.05 \pm 0.86$ [28]. The BSQ has shown to be highly internally consistent with a Cronbach's $\alpha$ of 0.88 , and it is reliable and valid [29]. It has also shown to be sensitive to detect changes in fear of body sensations after cognitive behavioural treatment among patients with NCCP [30]. 


\subsection{Statistical analysis}

In all questionnaires, missing data were imputed by substituting one to two missing values with the average of the non-missing items within each subscale [31,32]. Questionnaires with more than two missing values were disregarded.

Categorical variables are described in number and percentage, and were analysed with Chisquare tests. Continuous variables are described in mean values and standard deviations. Variables with normal distribution were analysed with Student's t-test. Skewed variables were analysed with Mann-Whitney U test and Kruskal Wallis test, i.e. differences in depressive symptoms, cardiac anxiety and fear of body sensations between groups (groups based on number of healthcare seeking occasions). Spearman correlation coefficient was used to describe the relationship between depressive symptoms, cardiac anxiety and fear of body sensations. To explore co-existence of depressive symptoms, cardiac anxiety and fear of body sensations in the participants, the median scores of the CAQ (24) and BSQ (28) were used as these lack cut-off scores. The cut-off score of 10 was used in the PHQ-9. Co-existence was calculated using crosstabs. To determine the independent relationship between depressive symptoms, cardiac anxiety and fear of body sensations, and healthcare seeking behaviour, healthcare seeking behaviour was categorised into two groups; 1 and $\geq 2$ healthcare seeking occasions, and used as the dependent variable in the multivariable logistic regression. The independent variables were continuous and entered in the regression model using the enter method. We controlled for age, sex and multi-morbidity. No problems with multicollinearity between the independent variables were detected according to the variance inflation factor (range 1.5-1.6). Differences were considered significant at $\mathrm{p}<.05$. IBM SPSS Statistics 22 was used in all statistical analyses. 


\section{RESULTS}

\subsection{Study participants}

Figure 1 presents the recruitment process. During the 3 months of data collection, a total of 2271 patients were eligible for study participation. Of these, 680 agreed to participate, but only 552 fulfilled both inclusion and exclusion criteria and were included in the study. Those who did not respond were significantly younger $(54 \pm 20$ years, $\mathrm{p}<.001)$ and tended to more often be males $(p=.054)$ compared to study participants. Those who declined participation were significantly older $(70 \pm 17$ years, $\mathrm{p}<.001)$.

Study participants were between 18 and 98 years old and had a mean age of $64( \pm 17)$ years. They were equally distributed with regard to sex, mainly born in Sweden (85 \%), married/cohabiting (67 \%), and retired (55 \%) (Table 1), and they reported a mean of 3.5 diseases/health complaints (Table 2), ranging from 0 to 12.

About $60 \%$ of the participants had sought care due to chest pain once, $26 \%$ two or three times, and the rest more than three times. Patients who sought care twice or more did not differ in age and sex, but they reported more diseases/health complaints (mean value 4.3 compared to 2.9, $\mathrm{p}<.001$ ) than those with one healthcare seeking occasion.

\subsection{Depressive symptoms, cardiac anxiety and fear of body sensations}

In the present study, the Cronbach's $\alpha$ coefficient was 0.87 for the PHQ-9, 0.90 for the total CAQ and 0.84, 0.89 and 0.76 for the subscales fear, avoidance, and heart-focused attention, and 0.93 for the BSQ.

Table 3 shows the scores of the PHQ-9, CAQ and BSQ in the study participants. In total, 26 $\%(n=141)$ of the participants reported depressive symptoms at a moderate level or higher (score $\geq 10$ ). 
The total cardiac anxiety score was $24.6 \pm 13.0$ and the mean score for each item was $1.4 \pm 0.7$. The scores of the subscales fear, avoidance and heart-focused attention were $1.6 \pm 0.9,1.3 \pm 1.0$, and $1.1 \pm 0.8$ respectively. According to the grading of the questionnaire, a score of one indicates rare prevalence of cardiac anxiety and a score of two indicates that cardiac anxiety is sometimes prevalent. About $42 \%(n=229)$ of the participants scored at least two, indicating at least moderate cardiac anxiety.

The total score of the BSQ was $31.4 \pm 12.1$ and the mean score for each item was $1.9 \pm 0.7$. According to the grading of the questionnaire, a score of two indicates being somewhat frightened by the sensation. In total, $62 \%(n=337)$ scored at least two, indicating at least some degree of fear of body sensations.

\subsection{Relationship between depressive symptoms, cardiac anxiety and fear of body sensations}

There was a strong positive relationship between depressive symptoms and cardiac anxiety $\left(\mathrm{r}_{\mathrm{s}}=0.49, \mathrm{p}<.01\right)$, depressive symptoms and fear of body sensations $\left(\mathrm{r}_{\mathrm{s}}=0.50, \mathrm{p}<.01\right)$, and cardiac anxiety and fear of body sensations $\left(\mathrm{r}_{\mathrm{s}}=0.56, \mathrm{p}<.01\right)$. Even though many participants suffered either from depressive symptoms, cardiac anxiety or fear of body sensations as illustrated in Table 4, at least two of these conditions were prevalent in $19 \%$ to $35 \%$ of the participants. We found that 112 (20\%) of the participants scored above both the cut-off of 10 in PHQ-9 and the median score of 24 in the CAQ. A total of 103 (19\%) of the participants scored both above the cut-off of 10 in PHQ-9 and the median score of 28 in the BSQ, and 195 (35 \%) scored above the medians of both CAQ and BSQ. 


\subsection{Relationship between depressive symptoms, cardiac anxiety, fear of body}

sensations, and healthcare seeking behaviour

Participants who sought care twice or more had significantly higher scores of depressive symptoms, cardiac anxiety (both the total score and all three subscales), and greater fear of body sensations than those who sought care on fewer occasions, see Table 3.

In the multiple regression analysis only cardiac anxiety was independently related to healthcare seeking behaviour, also after adjusting for multi-morbidity (OR 1.08, CI 1.06-1.10, $\mathrm{p}<.001$ ), see Table 5.

\section{DISCUSSION}

This is the first study examining the relationship between depressive symptoms, cardiac anxiety and fear of body sensations, and their relation to healthcare seeking behaviour in a large group of patients with NCCP. We found that depressive symptoms, cardiac anxiety and fear of body sensations were strongly related to each other and that many patients suffered from two of these conditions. Participants with two or more healthcare consultations had significantly higher scores of depressive symptoms, cardiac anxiety and fear of body sensations than those with one healthcare consultation. Cardiac anxiety was the only variable independently associated with healthcare seeking behaviour.

About $26 \%$ of the study participants suffered from at least moderate levels of depressive symptoms. This is comparable to our earlier study reporting depressive symptoms in $25 \%$ of the participants with NCCP [15]. The prevalence of depressive symptoms has been found to range from $9 \%$ to $40 \%$ in patients with NCCP [6]. Higher levels of depression severity have been found to be associated with an increase in healthcare use [15,26].

The participants in our study, especially those with more healthcare consultations, reported higher cardiac anxiety scores than anxious patients without panic and patients with panic [28], 
but also than a general population with mean scores substantially lower than one [33]. The high scores in our study are most likely due to recurrent episodes of chest pain to which no clear diagnosis has been found, leading to worries about having a cardiac illness, which also was concluded by Webster et al. [6]. When comparing non-cardiac and cardiac patients, those with non-cardiac diagnoses scored significantly higher on the fear and the heart-focused attention subscales [34]. Fear of body sensations was also more prevalent in those with more healthcare consultations. The participants in our study were somewhat frightened by their body sensations, and had higher scores than normal controls, but lower than patients with panic and agoraphobia [28,35]. In a study by Jonsbu et al. [30], patients with NCCP also scored similar to ours on the BSQ, and Goodacre et al. [36] found that a majority of the patients worried about their pain. If patients perceive the pain as threatening, this could lead to pain-related fear and safety seeking behaviour, such as avoidance $[37,38]$ and frequent visits to healthcare professionals [39]. Fear of cardiac sensations may also increase levels of perceived pain, resulting in greater disability and avoidance behaviour [40]. In our study, the mean avoidance score was low except in patients with many healthcare consultations. Repeated episodes of chest pain may cause pain-related fear, which leads to avoidance of the activity perceived to have started the chest pain. Fearful patients are more likely to misinterpret ambiguous physical sensations as threatening or painful, and are therefore at an increased risk of experiencing pain [38].

Since the CAQ lacks established cut-off scores, we chose to set the median score in our population as a cut-off to identify those with cardiac anxiety. Similar ways of defining and categorizing cardiac anxiety are prevalent in previous research. In a study by van Beek et al. [41], were the CAQ was used in cardiac patients, the authors used scores between 0-1 for low, 1-1.5 for intermediate, and above 1.5 for high anxiety levels based on latent class growth analysis. They suggested that a clinically relevant cut-off score could lie between the 
intermediate and the high scores. Another study exploring cardiac anxiety after sudden cardiac arrest used the scores in the upper quartile $(\mathrm{CAQ} \geq 1.81)$ for severe anxiety and the lowest quartile $(\mathrm{CAQ} \leq 0.73)$ for mild cardiac anxiety [42].

Also the BSQ lacks established cut-off scores, so we chose to use the same principle as for the CAQ. No studies were found using cut-off scores for defining prevalence of fear of body sensations other than mean score.

Although the CAQ and the BSQ were strongly correlated $\left(r_{s}=0.56\right)$ and had a common explained variance of about $30 \%$, we found that about $16-17 \%$ of the total study population had either cardiac anxiety or fear of body sensations. Therefore, the use of both questionnaires added to the results. Many of the participants suffered from a combination of depressive symptoms, cardiac anxiety and fear of body sensations. These findings confirm previous studies reporting on psychological distress and various mental disorders in patients with NCCP [20,43]. About $20 \%$ of the participants in our study reported having a history of mental disorder, but it was not obvious whether they had a combination of several disorders. This information is important when meeting with these patients and when designing interventions, as these disorders may require different approaches and may have different effects on the outcomes.

Although we found significant differences regarding depressive symptoms, cardiac anxiety and fear of body sensations in relation to number of healthcare seeking occasions, cardiac anxiety was the only variable in the regression analysis that was independently associated with healthcare seeking behaviour in the multivariate model. White et al. [20] also found an association between reported medical visits for chest pain and anxiety disorders, but not mood disorders including depression. This suggests that patients experiencing cardiac anxiety worry more about and pay more attention to cardiac symptoms due to fear of having a cardiac event, 
leading to greater use of healthcare. While fear can be seen as a normal reaction to pain which can be decreased by avoiding the cause of pain, anxiety is a more serious condition that is not easy to neglect, and that drives the individual to seek care. Based on the strong evidence for anxiety in patients with NCCP [6], we believe that anxiety may worsen the chest pain and create a 'vicious cycle', leading to maintenance of both anxiety and pain. Therefore, it is important to develop psychological interventions to target such anxiety, in order to break the vicious cycle and improve patient outcomes.

\subsection{Limitations}

About $30 \%$ of the approached patients agreed to participate. Although this is a relatively low response rate, it is not unusual. A recent review by Mcleod et al. [44] showed that about $30 \%$ of all surveys had a response rate of up to $39 \%$, and in many studies this information was not even provided. The low response rate can partly be explained by our broad inclusion criteria as no permission was given to review patient' medical records for suitable participants. Normally, patients with cognitive impairment, language difficulties, those living in nursing homes, and severely ill patients would not have been approached. If we had had access to such information, fewer patients would have been invited to participate, which probably would have increased our response rate significantly. We also examined a sensitive topic, used a quite extensive battery of questionnaires, did not provide the patients with a second battery of questionnaires together with the reminder, and had a large patient group. These factors may also have influenced the response rate [45-47]. In addition, we think that many of the participants who had chest pain for the very first time, presumably the younger ones, those under investigation for cardiac disease, or those with manifest angina pectoris did not consider the study to be relevant. It may also be the case that the older patients declined participation as it was perceived as burdensome. Still, the results are based on a sufficiently big sample that enables us to draw generalisable conclusions. 
The study was limited by the lack of a comparator group. The use of a cross-sectional design limits the possibility to determine the causal relationship between psychological distress and healthcare seeking behaviour. Also the fact that data is retrospective, and self-reported at one occasion could be a limitation.

\section{CONCLUSIONS AND CLINICAL IMPLICATIONS}

Patients with NCCP and many healthcare consultations had high levels of depressive symptoms and cardiac anxiety, and moderate levels of fear of body sensations. Cardiac anxiety had the strongest relationship with healthcare seeking behaviour, and may therefore be an important target for intervention to alleviate suffering and reduce healthcare use and costs. By reducing cardiac anxiety, patients may be better prepared to handle chest pain, which also could lead to decreased and less prominent symptoms of NCCP.

Although depressive symptoms were not independently associated with healthcare seeking behaviour, these were highly prevalent in the participants. We therefore suggest that patients with NCCP should be screened for depressive symptoms and provided with an effective treatment.

\section{ACKNOWLEDGEMENT}

This study was supported by the County Council of Östergötland, Sweden and the Medical Research of Southeast Sweden (FORSS). A special thanks to Kristofer Årestedt for advice on the statistics and to Sofia McGarvey for language check.

\section{AUTHOR CONTRIBUTIONS}

All authors contributed to the conception and design of the study. The first author (GM) collected the data and performed the statistical analysis in discussion with the other authors. All 
authors contributed to the analysis and interpretation of the data, and drafting of the manuscript.

The first author had the main responsibility and is the guarantor for the study.

\section{COMPETING INTERESTS}

The authors declare that they have no competing interests to disclose. 


\section{REFERENCES}

1. Eslick GD. Classification, natural history, epidemiology, and risk factors of noncardiac chest pain. Dis Mon 2008;54:593-603.

2. Eslick GD, Talley NJ. Non-cardiac chest pain: predictors of health care seeking, the types of health care professional consulted, work absenteeism and interruption of daily activities. Aliment Pharmacol Ther 2004;20:909-915.

3. Lenfant C. Chest pain of cardiac and noncardiac origin. Metabolism 2010;59 Suppl 1:S416.

4. Ruddox V, Mathisen M, Otterstad JE. Prevalence and prognosis of non-specific chest pain among patients hospitalized for suspected acute coronary syndrome - a systematic literature search. BMC Med 2012;10:58. doi: 10.1186/1741-7015-10-58.

5. Fass R, Achem SR. Noncardiac chest pain: epidemiology, natural course and pathogenesis. J Neurogastroenterol Motil 2011;17:110-123.

6. Webster R, Norman P, Goodacre S, et al. The prevalence and correlates of psychological outcomes in patients with acute non-cardiac chest pain: a systematic review. Emerg Med J 2012;29:267-273.

7. Reid S, Wessely S, Crayford T, et al. Medically unexplained symptoms in frequent attenders of secondary health care: retrospective cohort study. BMJ 2001;322:767.

8. Spalding L, Reay E, Kelly C. Cause and outcome of atypical chest pain in patients admitted to hospital. J R Soc Med 2003;96:122-125.

9. Eifert GH, Hodson SE, Tracey DR, et al. Heart-focused anxiety, illness beliefs, and behavioral impairment: comparing healthy heart-anxious patients with cardiac and surgical inpatients. J Behav Med 1996;19:385-399.

10. Klimes I, Mayou RA, Pearce MJ, et al. Psychological treatment for atypical non-cardiac chest pain: a controlled evaluation. Psychol Med 1990;20:605-611.

11. Esler JL, Bock BC. Psychological treatments for noncardiac chest pain: recommendations for a new approach. J Psychosom Res 2004;56:263-269.

12. Fagring AJ, Lappas G, Kjellgren KI, et al. Twenty-year trends in incidence and 1-year mortality in Swedish patients hospitalised with non-AMI chest pain. Data from 1987-2006 from the Swedish hospital and death registries. Heart 2010;96:1043-1049.

13. Leise MD, Locke GR,3rd, Dierkhising RA, et al. Patients dismissed from the hospital with a diagnosis of noncardiac chest pain: cardiac outcomes and health care utilization. Mayo Clin Proc 2010;85:323-330.

14. Eslick GD. Health care seeking behaviors, psychological factors, and quality of life of noncardiac chest pain. Dis Mon 2008;54:604-612. 
15. Mourad G, Jaarsma T, Hallert C, et al. Depressive symptoms and healthcare utilization in patients with noncardiac chest pain compared to patients with ischemic heart disease. Heart Lung 2012;41:446-455.

16. Eslick GD, Coulshed DS, Talley NJ. Review article: the burden of illness of non-cardiac chest pain. Aliment Pharmacol Ther 2002;16:1217-1223.

17. Forberg JL, Henriksen LS, Edenbrandt L, et al. Direct hospital costs of chest pain patients attending the emergency department: a retrospective study. BMC Emerg Med 2006;6:6.

18. Groarke J, O'Brien J, Go G, et al. Cost burden of non-specific chest pain admissions. Ir J Med Sci 2013;182:57-61.

19. Mourad G, Alwin J, Stromberg A, et al. Societal costs of non-cardiac chest pain compared with ischemic heart disease--a longitudinal study. BMC Health Serv Res 2013; 13:403. doi: 10.1186/1472-6963-13-403.

20. White KS, Raffa SD, Jakle KR, et al. Morbidity of DSM-IV Axis I disorders in patients with noncardiac chest pain: Psychiatric morbidity linked with increased pain and health care utilization. J Consult Clin Psychol 2008;76:422-430.

21. Hadlandsmyth K, Rosenbaum DL, Craft JM, et al. Health care utilisation in patients with non-cardiac chest pain: a longitudinal analysis of chest pain, anxiety and interoceptive fear. Psychol Health 2013;28:849-861.

22. Hadlandsmyth K, White KS, Krone RJ. Quality of life in patients with non-CAD chest pain: associations to fear of pain and psychiatric disorder severity. J Clin Psychol Med Settings 2013;20:284-293.

23. Smeijers L, van de Pas H, Nyklicek I, et al. The independent association of anxiety with non-cardiac chest pain. Psychol Health 2014;29:253-263.

24. Webster R, Norman P, Goodacre S, et al. Illness representations, psychological distress and non-cardiac chest pain in patients attending an emergency department. Psychol Health 2014;29(11):1265-82.

25. Kriegsman DM, Penninx BW, van Eijk JT, et al. Self-reports and general practitioner information on the presence of chronic diseases in community dwelling elderly. A study on the accuracy of patients' self-reports and on determinants of inaccuracy. J Clin Epidemiol 1996;49:1407-1417.

26. Kroenke K, Spitzer RL, Williams JB. The PHQ-9: validity of a brief depression severity measure. J Gen Intern Med 2001;16:606-613.

27. Eifert GH, Thompson RN, Zvolensky MJ, et al. The cardiac anxiety questionnaire: development and preliminary validity. Behav Res Ther 2000;38:1039-1053.

28. Carlbring P. Formulärsammanställning_028.

2005. http://www.carlbring.se/form/formularsammanstallning.pdf. Accessed March 2014. 
29. Chambless DL, Caputo GC, Bright P, et al. Assessment of fear of fear in agoraphobics: the body sensations questionnaire and the agoraphobic cognitions questionnaire. J Consult Clin Psychol 1984;52:1090-1097.

30. Jonsbu E, Dammen T, Morken G, et al. Short-term cognitive behavioral therapy for noncardiac chest pain and benign palpitations: a randomized controlled trial. J Psychosom Res 2011;70:117-123.

31. Hoyer J, Eifert GH, Einsle F, et al. Heart-focused anxiety before and after cardiac surgery. J Psychosom Res 2008;64:291-297.

32. Kroenke K, Spitzer RL, Williams JB, et al. The Patient Health Questionnaire Somatic, Anxiety, and Depressive Symptom Scales: a systematic review. Gen Hosp Psychiatry 2010;32:345-359.

33. Fischer D, Kindermann I, Karbach J, et al. Heart-focused anxiety in the general population. Clin Res Cardiol 2012;101:109-116.

34. Marker CD, Carmin CN, Ownby RL. Cardiac anxiety in people with and without coronary atherosclerosis. Depress Anxiety 2008;25:824-831.

35. Ruwaard J, Broeksteeg J, Schrieken B, et al. Web-based therapist-assisted cognitive behavioral treatment of panic symptoms: a randomized controlled trial with a three-year follow-up. J Anxiety Disord 2010;24:387-396.

36. Goodacre S, Mason S, Arnold J, et al. Psychologic morbidity and health-related quality of life of patients assessed in a chest pain observation unit. Ann Emerg Med 2001;38:369-376.

37. Mayou R. Chest pain, palpitations and panic. J Psychosom Res 1998;44:53-70.

38. Leeuw M, Goossens ME, Linton SJ, et al. The fear-avoidance model of musculoskeletal pain: current state of scientific evidence. J Behav Med 2007;30:77-94.

39. Quartana PJ, Campbell CM, Edwards RR. Pain catastrophizing: a critical review. Expert Rev Neurother 2009;9:745-758.

40. Aikens JE, Zvolensky MJ, Eifert GH. Differential fear of cardiopulmonary sensations in emergency room noncardiac chest pain patients. J Behav Med 2001;24:155-167.

41. van Beek MH, Mingels M, Voshaar RC, et al. One-year follow up of cardiac anxiety after a myocardial infarction: a latent class analysis. J Psychosom Res 2012;73:362-368.

42. Rosman L, Whited A, Lampert R, et al. Cardiac anxiety after sudden cardiac arrest: Severity, predictors and clinical implications. Int J Cardiol 2014;181C:73-76.

43. Husser D, Bollmann A, Kuhne C, et al. Evaluation of noncardiac chest pain: diagnostic approach, coping strategies and quality of life. Eur J Pain 2006;10:51-55.

44. McLeod CC, Klabunde CN, Willis GB, et al. Health care provider surveys in the United States, 2000-2010: a review. Eval Health Prof 2013;36:106-126. 
45. Nakash RA, Hutton JL, Jorstad-Stein EC, et al. Maximising response to postal questionnaires--a systematic review of randomised trials in health research. BMC Med Res Methodol 2006;6:5.

46. Edwards P, Roberts I, Clarke M, et al. Methods to increase response rates to postal questionnaires. Cochrane Database Syst Rev 2007;(2):MR000008.

47. Cook JV, Dickinson HO, Eccles MP. Response rates in postal surveys of healthcare professionals between 1996 and 2005: an observational study. BMC Health Serv Res 2009;9:160. doi: 10.1186/1472-6963-9-160. 
Table 1: Characteristics of patients with non-cardiac chest pain, $\mathrm{N}=552$

\begin{tabular}{|c|c|c|}
\hline & Frequency (n) & Percentage (\%) \\
\hline Age year (mean \pm SD) & $63.8 \pm 16.6$ & \\
\hline Females & 281 & 51 \\
\hline \multicolumn{3}{|l|}{ Birth country } \\
\hline Sweden & 470 & 85 \\
\hline Other Nordic countries & 22 & 4 \\
\hline Non-Nordic European countries & 37 & 7 \\
\hline South America & 3 & .5 \\
\hline Africa & 2 & .4 \\
\hline Asia & 18 & 3 \\
\hline Married/cohabiting & 370 & 67 \\
\hline \multicolumn{3}{|l|}{ Educational level } \\
\hline Compulsory school & 165 & 30 \\
\hline High school & 216 & 39 \\
\hline University & 150 & 27 \\
\hline Other & 20 & 4 \\
\hline \multicolumn{3}{|l|}{ Work status } \\
\hline Workers & 152 & 28 \\
\hline Retired & 302 & 55 \\
\hline Sick-leave/disability pension & 40 & 7 \\
\hline Unemployed & 21 & 4 \\
\hline Students & 19 & 3 \\
\hline Other & 17 & 3 \\
\hline BMI $\left(\mathrm{kg} / \mathrm{m}^{2}\right)($ mean \pm SD $)$ & $26.6 \pm 4.9$ & \\
\hline \multicolumn{3}{|l|}{ BMI $\left(\mathrm{kg} / \mathrm{m}^{2}\right)$} \\
\hline$<19$ & 8 & 1 \\
\hline $19-25$ & 239 & 43 \\
\hline $26-30$ & 206 & 37 \\
\hline$>30$ & 99 & 18 \\
\hline \multicolumn{3}{|l|}{ Smoking n (\%) } \\
\hline None/previous smokers & 493 & 89 \\
\hline Smokers & 59 & 11 \\
\hline \multicolumn{3}{|l|}{ Alcohol consumption n (\%) } \\
\hline None & 141 & 26 \\
\hline 1-7 glasses/week & 390 & 71 \\
\hline >7 glasses/week & 20 & 4 \\
\hline \multicolumn{3}{|l|}{ Exercise n (\%) } \\
\hline$<1$ hour/week & 232 & 42 \\
\hline 1-3 hours/week & 179 & 32 \\
\hline >3 hours/week & 140 & 25 \\
\hline
\end{tabular}


Table 2: Self-reported illness background in patients with non-cardiac chest pain, n (\%). N=552

\begin{tabular}{lrrrr}
\hline No & $\begin{array}{r}\text { Yes, but I have not } \\
\text { consulted a physician/ } \\
\text { had treatment last year }\end{array}$ & $\begin{array}{r}\text { Yes, I have consulted a } \\
\text { physician/had treatment } \\
\text { last year }\end{array}$ & Missing \\
\hline Musculoskeletal pain & $236(43)$ & $168(30)$ & $139(25)$ & $9(2)$ \\
Hypertension & $60(11)$ & $187(34)$ & $8(1)$ \\
Reflux/heartburn & $297(54)$ & $147(27)$ & $87(16)$ & $8(1)$ \\
Headache/migraine & $310(56)$ & $164(30)$ & $49(9)$ & $8(1)$ \\
Angina Pectoris & $331(60)$ & $31(6)$ & $83(15)$ & $16(3)$ \\
Mental disorder & $422(76)$ & $47(9)$ & $60(11)$ & $10(2)$ \\
Myocardial infarction & $435(79)$ & $23(4)$ & $81(15)$ & $6(1)$ \\
Cancer & $442(80)$ & $35(6)$ & $35(6)$ & $9(2)$ \\
Bowel disease & $473(86)$ & $22(4)$ & $45(8)$ & $8(1)$ \\
Asthma/bronchitis & $477(86)$ & $22(4)$ & $44(8)$ & $8(1)$ \\
Rheumatism & $478(87)$ & $27(5)$ & $35(6)$ & $11(2)$ \\
Diabetes & $479(87)$ & $8(1)$ & $56(10)$ & $7(1)$ \\
Heart failure & $481(87)$ & $14(3)$ & $41(7)$ & $15(3)$ \\
Gastric ulcer & $482(87)$ & $26(5)$ & $22(4)$ & $10(2)$ \\
Chronic obstructive & $494(89)$ & $12(2)$ & $25(5)$ & $8(1)$ \\
pulmonary disease & $507(92)$ & $26(5)$ & & \\
Liver disease/ & & $12(2)$ & $6(1)$ \\
gallbladder disease & $508(92)$ & $11(2)$ & $15(3)$ & $11(2)$ \\
Kidney disease & $509(92)$ & $8(1)$ & $9(2)$ & $20(4)$ \\
Stroke & $512(93)$ & $2(.4)$ & $5(1)$ & $11(2)$ \\
Pressure sore & $528(96)$ & - & $5(1)$ & $7(1)$ \\
Parkinson's disease & $538(97)$ & $1(.2)$ & $3(.5)$ & $11(2)$ \\
Connective Tissue Disease & $538(97)$ & & $3(.5)$ & $8(1)$ \\
Multiple sclerosis & $540(98)$ & & & \\
\hline
\end{tabular}


Table 3: Scores of PHQ-9, CAQ and BSQ in patients with non-cardiac chest pain, based on healthcare seeking behaviour, mean \pm SD

\begin{tabular}{|c|c|c|c|c|c|}
\hline & $\begin{array}{r}\text { All } \\
\text { patients } \\
(\mathrm{N}=552) \\
\end{array}$ & $\begin{array}{r}\text { Patients with } 1 \\
\text { healthcare seeking } \\
\text { occasion/year } \\
(n=331)\end{array}$ & $\begin{array}{r}\text { Patients with } 2-3 \\
\text { healthcare seeking } \\
\text { occasions/year } \\
(n=145)\end{array}$ & $\begin{array}{r}\text { Patients with }>3 \\
\text { healthcare seeking } \\
\text { occasions/year } \\
(\mathrm{n}=76)\end{array}$ & P-value \\
\hline \multicolumn{6}{|l|}{ Patient Health } \\
\hline \multicolumn{6}{|l|}{ Questionnaire, PHQ-9 } \\
\hline Total score & $6.4 \pm 5.9$ & $5.1 \pm 5.0$ & $7.3 \pm 5.9$ & $10.4 \pm 7.1$ & $<.001^{*}$ \\
\hline Missing n (\%) & $1(.2)$ & $1(.2)$ & - & - & \\
\hline \multicolumn{6}{|l|}{ Cardiac Anxiety } \\
\hline \multicolumn{6}{|l|}{ Questionnaire, CAQ } \\
\hline Total score & $24.6 \pm 13.0$ & $20.0 \pm 11.1$ & $29.2 \pm 11.8$ & $36.1 \pm 12.5$ & $<.001 *$ \\
\hline Mean score & $1.4 \pm 0.7$ & $1.1 \pm 0.6$ & $1.6 \pm 0.7$ & $2.0 \pm 0.7$ & $<.001 *$ \\
\hline - Fear & $1.6 \pm 0.9$ & $1.4 \pm 0.8$ & $1.9 \pm 0.7$ & $2.3 \pm 0.7$ & $<.001 *$ \\
\hline - Avoidance & $1.3 \pm 1.0$ & $1.0 \pm 0.9$ & $1.5 \pm 1.0$ & $1.9 \pm 1.0$ & $<.001 *$ \\
\hline - Heart-focused attention & $1.1 \pm 0.8$ & $0.8 \pm 0.6$ & $1.3 \pm 0.7$ & $1.7 \pm 0.8$ & $<.001 *$ \\
\hline Missing n (\%) & $2(.4)$ & - & $2(1.4)$ & - & \\
\hline \multicolumn{6}{|l|}{ Body Sensations } \\
\hline \multicolumn{6}{|l|}{ Questionnaire, BSQ } \\
\hline Total score & $31.4 \pm 12.1$ & $29.3 \pm 11.3$ & $32.7 \pm 12.0$ & 37. $9 \pm 13.1$ & $<.001 *$ \\
\hline Mean score & $1.9 \pm 0.7$ & $1.7 \pm 0.7$ & $1.9 \pm 0.7$ & $2.2 \pm 0.8$ & $<.001 *$ \\
\hline Missing n (\%) & $5(.9)$ & $4(1.2)$ & - & $1(1.3)$ & \\
\hline
\end{tabular}

*Kruskal Wallis test and Mann-Whitney U test showed significant differences between all groups 
Table 4: Co-existence of depressive symptoms (PHQ-9), cardiac anxiety (CAQ) and fear of body sensations (BSQ) in patients with non-cardiac chest pain, $\mathrm{N}=552$

\begin{tabular}{lccc}
\hline & PHQ-9 $\geq \mathbf{1 0}$ & CAQ-score $\geq 24$ & BSQ -score $\geq 28$ \\
\hline PHQ-9 $\geq \mathbf{1 0}$ & $26 \%(\mathrm{n}=141)$ & \\
CAQ-score $\geq \mathbf{2 4}$ & $20 \%(\mathrm{n}=112)$ & $51 \%(\mathrm{n}=283)$ & \\
BSQ -score $\geq \mathbf{2 8}$ & $19 \%(\mathrm{n}=103)$ & $35 \%(\mathrm{n}=195)$ & $52 \%(\mathrm{n}=287)$ \\
\hline
\end{tabular}


Table 5: Multivariable logistic regression analysis revealing the independent relationship between depressive symptoms, cardiac anxiety, fear of body sensations, and healthcare seeking behaviour. Analysis adjusted for multi-morbidity

\section{Healthcare seeking behaviour}

\begin{tabular}{lccccc}
\hline Explanatory variables & B & S.E. & Odds ratio & $\begin{array}{c}\text { 95 \% confidence } \\
\text { interval (CI) }\end{array}$ & p-value \\
\hline Depressive symptoms & .017 & .021 & 1.02 & $.98-1.06$ & .423 \\
Cardiac anxiety & .077 & .011 & 1.08 & $1.06-1.10$ & $<.001$ \\
Fear of body sensations & -.014 & .011 & .99 & $.97-1.01$ & .172 \\
\hline
\end{tabular}

(Goodness of fit Hosmer-Lemeshow chi-square coefficient $=10.9$, p-value $=.208$ ) 


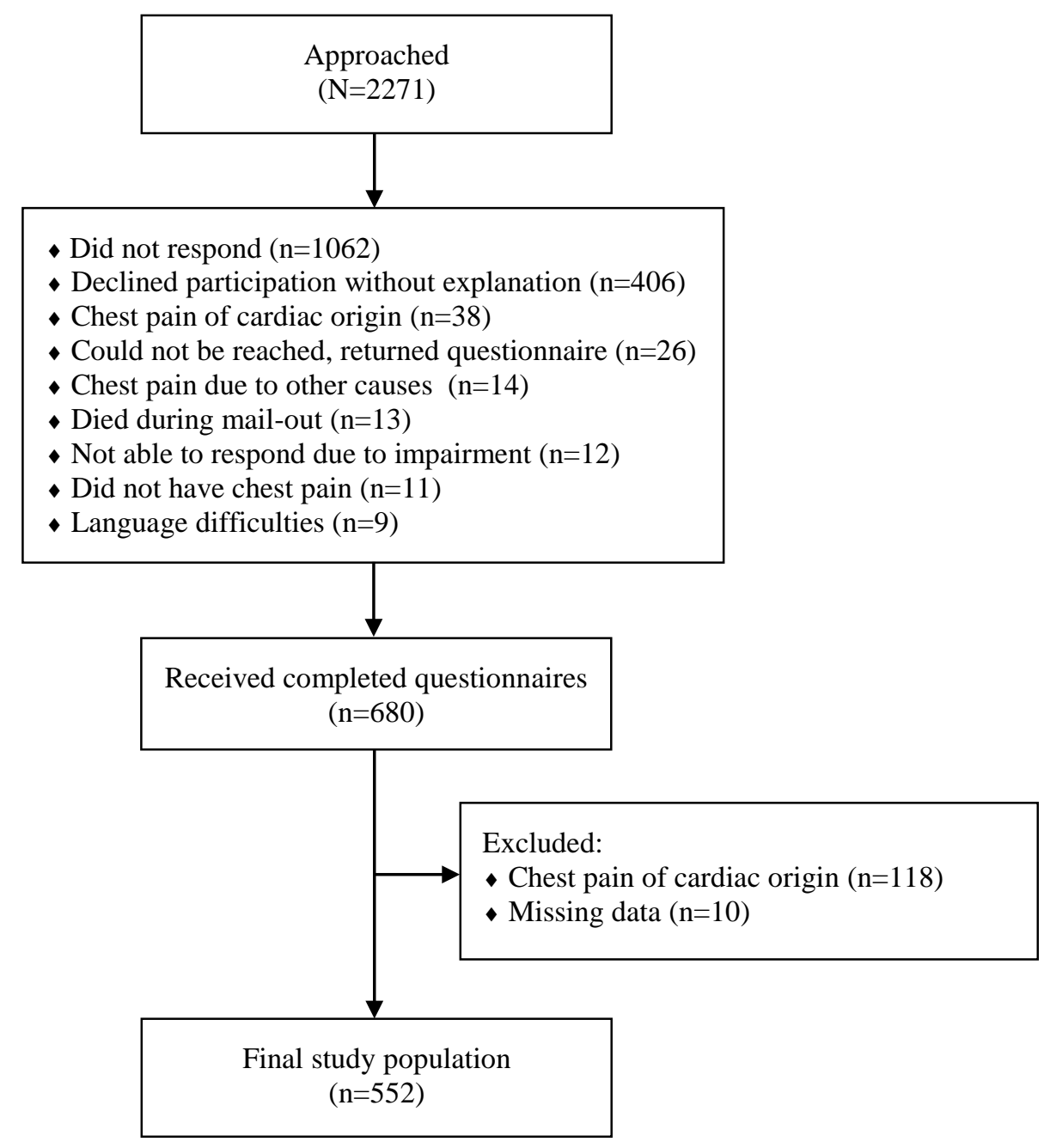

Figure 1: Recruitment of study participants 